\title{
COMUNICACCÃO MEDIADA PELO COMPUTADOR: BLOG - GÊNERO DISCURSIVO EMERGENTE
}

\author{
Joana Ormundo
}

\begin{abstract}
This paper examines the language of the blogs from the point of view of Critical Discourse Analysis as it is conceived by Norman Fairclough. The main aim is to analyse discourse practices in the on-line context. The interactive process and the constitution of discourse community in blogs will be examined according to the genre analysis approach developed by Bakhtin (1997) and the concept of discourse community developed by Swales(1990).
\end{abstract}

Key words: Language, identity, discourse community, genre.

\section{INTRODUÇÃO}

\begin{abstract}
A língua penetra na vida através dos enunciados concretos que a realizam, e é também através dos enunciados concretos que a vida penetra na língua. $\mathrm{O}$ enunciado situa-se no cruzamento excepcionalmente importante de uma problemática. É deste ângulo que vamos agora abordar algumas áreas e alguns problemas da lingüística. (Bakhtin, trad., 1997: 282)
\end{abstract}

Propõe-se investigar, neste artigo, as formas de comunicação dos sujeitos que interagem em contextos midiáticos. Para isso, serão examinadas as práticas sociais nas linguagens usadas nas novas tecnologias, verificando se essas práticas constituem uma comunidade discursiva que forma um novo gênero discursivo. No primeiro momento, contextualizaremos o(a) leitor(a) sobre o universo das práticas de comunicação global mediada por computador (CMC). Iniciaremos com um breve histórico sobre o desenvolvimento da Internet, tendo como base os estudos de Castells (2003). No segundo momento, delimitaremos o estudo das formas comunicativas examinando 
as práticas de linguagem que acontecem nos blogs, o que permitirá destacar as concepções de linguagem, texto, significado e gênero discursivo que orientam nossa análise. No terceiro momento, recorreremos aos estudos desenvolvidos por J. M. Swales (1990) sobre as características que definem uma comunidade discursiva, com a finalidade de correlacioná-las com as práticas de linguagem observadas nos blogs. Buscar-se-á verificar se essas práticas permitem identificá-los como um novo gênero discursivo. Por último, analisaremos algumas estratégias comunicativas nos blogs.

\section{BREVE HISTÓRICO SOBRE O AVANÇO DA INTERNET NA SOCIEDADE PÓS-MODERNA}

As práticas sociais com a linguagem por meio da CMC têm crescido consideravelmente se considerarmos os estudos realizados por Castells (2003), no período da década de 1999 até 2003, sobre o impacto da Internet na sociedade pós-moderna. Os dados apresentados pelo autor têm demonstrado a velocidade da penetração da Internet na sociedade, mediante o impacto desta nova tecnologia em comparação ao ocorrido com outros meios de comunicação. Castells aponta que em uma proporção de uso dos meios de comunicação desde a sua criação até atingir um número de usuários na escala de sessenta milhões de pessoas, o rádio precisou de trinta anos, a televisão de 15 anos, enquanto a Internet abarcou esses números em apenas três anos de uso.

Apesar deste crescimento acelerado há, por outro lado, uma desigualdade entre os usuários da rede, conforme demonstra a análise de Castells (2003). O quadro de usuários da rede acompanha, então, o seguinte perfil: predomínio em países industrializados, predomínio de usuários com nível superior $(61,6 \%)$, probabilidade 20 vezes maior de usuários com renda mais alta do que os de renda mais baixa, maior número de homens, faixa etária média de até 36 anos nos EUA e abaixo de 30 anos em países como a Rússia e a China.

Com o crescimento acelerado da Internet, surge um processo diferenciado das práticas comunicativas por meio da inserção desta nova tecnologia. Há um processo interativo nas relações comunicativas muito mais evidenciado do que em outros contextos midiáticos. Castells (2003) 
define esse processo interativo com o formato da World Wide Web (www) que estabeleceu a rede de alcance mundial, como uma rede flexível formada por redes dentro da Internet, de tal modo que instituições, empresas, associações e pessoas físicas podem criar os próprios sítios (sites). $\mathrm{O}$ formato da rede www permite que todos os indivíduos com acesso à rede possam produzir sua página e outras ferramentas disponíveis.

As redes de CMC, dentro e fora da Internet, têm como características: penetrabilidade, descentralização multifacetada eflexibilidade. Avançam rapidamente e refletem interesses pessoais, comerciais, institucionais na esfera da comunicação. Possuem propriedades de interatividade e individualização tecnológica embutidas. É neste universo que se faz necessário investigar se esta nova tecnologia e a rapidez com que ela tem evoluído, em tempos atuais, impõem novos padrões de comunicação.

\section{Conceito De BLog, Linguagem, texto E Significado}

Dentro do universo de práticas comunicativas que surgem na Internet, voltaremos nossa atenção para as que ocorrem nos blogs, que podem ser considerados como um sistema padronizado de publicação na Internet. Há uma padronização de publicação de textos narrativos que são ordenados cronologicamente, razão pela qual o formato dessa ferramenta permite que os produtores dos textos atualizem os fatos de forma mais rápida que um sítio. Como não há a necessidade de conhecimento técnico para a formatação e criação dessas páginas, temos percebido uma popularização desse tipo de publicação de textos, que serão denominados neste trabalho como diários on line.

Os textos construídos nos blogs caminham para uma desconstrução de abordagens narrativas situadas no universo da modernidade, impondo uma mudança de paradigma no trato com a linguagem e abandonando os modelos tradicionais. Além disso, abrem espaço para a compreensão das novas formas de organização das linguagens em uma sociedade pós-moderna. A compreensão dessa mudança de paradigma sugere uma discussão sobre as formas de linguagem que superam todas as formas de reducionismo. As narrativas publicadas nos blogs expõem fatos do cotidiano, vida pessoal, 
preferência musical, cinema, teatro, textos literários, poesias, crônicas, comentário de livros, situações polêmicas, relatos de acontecimentos íntimos e assim por diante, por meio de um processo dialógico e uma pluralidade de uso das linguagens. $\mathrm{O}$ intuito é que as experiências pessoais sejam compartilhadas por todos que acessam aos blogs, o que é muito diferente da prática tradicional de diários em que os segredos eram trancados a sete chaves.

As práticas discursivas que ocorrem nos blogs orientam-nos para uma compreensão dos aspectos dialógicos da linguagem, como formulado por Bakhtin (1997) e que se constitui tanto no processo interativo como na construção do sentido do discurso.

A pluralidade das linguagens que circulam no ambiente dos blogs também nos remete a uma perspectiva teórica que amplia o conceito de texto. Halliday \& Hasan (1985) definem texto como qualquer instância de linguagem em uso que está ocorrendo em um determinado contexto situacional, podendo ser falado, escrito ou em qualquer outro meio de expressão. O texto é definido pelos autores como unidade semântica, o que nos convida a olhar toda a rede de significações que está nos blogs (o oral, o escrito e o visual). Essa ampliação implica novo olhar - além das palavras e estruturas.

A sociossemiótica formulada por Halliday \& Hasan (1985) amplia a noção de significado não-preso a estruturas da sentença, mas inserido na relação dialógica, logo o contexto em que as práticas comunicativas ocorrem são fundamentais para desvelar a rede de sentidos dos textos ${ }^{1}$. A construção dos sentidos do texto caminha na ampliação das noções de linguagem, agora não mais restrita à oralidade e à escrita, mas entendida como formas de significação decorrentes dos contextos em que elas ocorrem.

\section{A EMERgÊnCIA de nOvos GÊNEROS NA ERA DA INTERneT}

A Internet funciona como suporte de um conjunto bastante amplo de eventos de natureza diversa. Com o avanço da Internet, de início o uso dos chats (canais de bate-papo sincrônico), sites (conjunto de páginas

\footnotetext{
${ }^{1}$ Magalhães, I. e Leal, M. C. (orgs.), 2003; Martins, 2003.
} 
da internet), e agora com a explosão dos blogs (suporte de diários on line), faz-se necessário discutir os aspectos que envolvem a criação de um novo gênero discursivo nesse novo contexto midiático.

\subsection{CONCEITO DE GÊNERO DISCURSIVO}

Estabeleceremos uma discussão sobre o conceito de gênero discursivo. Nesse sentido, o conceito de gênero adotado neste trabalho difere das definições de gênero como modalidade da escrita e vinculado às tipologias textuais. Trataremos a questão do gênero como aquela associada às esferas da atividade humana como apresentadas nos estudos bakhtinianos (1997). A relevância do trabalho de Bakhtin sobre gênero consiste na relação que esse autor estabelece sobre a heterogeneidade e dinamicidade dos gêneros. É na dinâmica de um processo comunicativo, situado em determinado contexto social, que se percebe a interação de um gênero com outro(s) para se constituir como tal. Para Bakhtin, os gêneros do discurso são tipos relativamente estáveis de enunciados. Uma vez que as esferas sociais são heterogêneas e dinâmicas, os gêneros discursivos também são heterogêneos e dinâmicos. Bakhtin também define os gêneros como categorias históricas, aparentemente estáveis, pois estão sujeitas a um processo de transformação contínua. Nesse sentido, podemos inferir que os gêneros existentes mudam seguindo as modificações na situação social na qual exercem uma função ou novos gêneros podem surgir de transformações dos gêneros já existentes. Para Bakhtin, há tipos de enunciados padronizados, que são empregados em determinadas situações, não havendo a recriação de forma e conteúdo toda vez que há uma situação comunicativa nova.

\subsection{BLOGS: A EMERGÊNCIA DE UM NOVO GÊNERO DISCURSIVO}

Nossa concepção de gênero discursivo situa-se nas práticas sociais com a linguagem ${ }^{2}$. É nessas práticas que os sujeitos criam uma estrutura comunicativa configurada em forma-padrão e determinada pelos contextos sociais, históricos, temporais, espaciais e ideológicos que as antecederam. Os blogs

\footnotetext{
${ }^{2}$ Meurer e Motta-Roth (orgs.), 2002.
} 
surgem dentro desse contexto e, apesar de funcionarem como suporte de gêneros já existente, ao relembrar o formato de diário pessoal, anotações e agendas e considerando a natureza híbrida dos textos que compõem os blogs, ocorre que, ao mesmo tempo, eles aparecem como criadores de outros gêneros com características próprias que deverão ser analisadas ${ }^{3}$.

Os blogs aproximam-se do gênero diário tradicional, por enfatizar narrativas de cunho pessoal. Os sujeitos produtores de blogs narram acontecimentos íntimos, pessoais, mantendo uma ordenação cronológica dos fatos narrados, o que é muito bem caracterizado como prática de diário pessoal.

Os blogs surgiram no final da década de 1990, portanto são recentes. No primeiro momento de seu surgimento, podemos verificar, por meio dos mecanismos de formatação dos blogs, a aproximação à prática discursiva de diários pessoais, confirmando a definição bakhtiniana sobre a transmutação de gêneros já consagrados no processo de formação de novos gêneros.

O formato de publicação on line, diferentemente dos modelos tradicionais de publicação de diários, possibilita que os produtores de blogs construam narrativas de forma mais dinâmica e interativa. Essa dinâmica vem marcada pelo uso da própria ferramenta, pelo meio de publicação do texto, e, principalmente, pelo caráter interativo que a ferramenta possibilita, muito diferentemente do gênero que o inspirou inicialmente que é definido neste trabalho como diários off line. Essa interatividade vem marcada, também, pela natureza híbrida das construções dos enunciados produzidos nos blogs. Há uma dinamicidade muito grande no uso das linguagens. Trazem textos multimodais (Kress e van Leeuwen, 1996), por meio da inserção de várias linguagens: oral, escrita, fotográfica, imagem, voz, música, ruídos, movimentos. $\mathrm{O}$ hibridismo mostra-se como a própria condição estrutural dos textos produzidos nas novas tecnologias, especificamente nos blogs.

Há necessidade de um estudo mais sistematizado sobre essa nova prática social com a linguagem, acompanhando seu impacto no contexto social em que ela aparece, para investigarmos, detalhadamente, se ela constitui um novo gênero. Essa investigação mais sistematizada não implica que, nesse período de existência dos blogs, não seja possível identificar nele

${ }^{3}$ Santos, 2003. 
uma historicidade, uma funcionalidade e uma estruturação específica que permitem caracterizá-lo como gênero híbrido, conforme já apresentado por outros pesquisadores. Mas, ainda é prematuro afirmar, sem um estudo mais sistematizado, o desenvolvimento do blog como um novo gênero.

Em busca dessa sistematização e, considerando que uma prática social com a linguagem para se caracterizar como gênero discursivo deve se impor como uma comunidade discursiva, decidimos, nesse primeiro momento, analisar estruturas de linguagem nos blogs que possam caracterizá-los como pertencentes a uma comunidade dicursiva.

Para esta análise, recorreremos ao trabalho de J. M. Swales (1990) que estabelece seis características que permitirão identificar se um grupo de indivíduos, em determinada atividade prática com a linguagem, constitui uma comunidade discursiva.

\subsection{Blogs E COMUNIDAdE DISCURSIVA: UMA BREVE ANÁLISE DAS PRÁTICAS DE LINGUAGEM}

A primeira característica formulada por Swales consiste em que os membros de uma comunidade discursiva necessitam ter objetivos comuns. Segundo o autor, tais objetivos podem vir explicitados em cláusulas de entidades institucionais, tais como clubes, associações e instituições. Mas o fato de os indivíduos se agruparem em uma mesma instituição, não significa, necessariamente, que os seus membros devam compartilhar os mesmos objetivos. Um bom exemplo exposto por Swales consiste no fato de determinados representantes partidários fazerem parte de uma mesma instituição, como o Senado ou Parlamento e, nesse mesmo contexto, coexistirem membros de grupos adversários que, em algum momento, compartilham de objetivos comuns, mas não de todos.

Conforme discussão anterior, podemos inferir que o blog como ferramenta que hospeda os diários on-line não se constitui por si só uma comunidade discursiva, dada a natureza híbrida dos interesses pessoais que motivam seus participantes. Mas, verificamos no universo dos blogs indivíduos que se agrupam por temas de interesses pessoais, tais como: narrativas de viagens, universo do mundo adolescente, discussões políticas, discussões acadêmicas, grupos literários e assim por diante. 
De outro modo, se considerarmos esses agrupamentos motivados por temáticas de interesse do grupo, podemos inferir, dessa forma, a existência de uma comunidade discursiva no universo dos blogs. A comunidade discursiva não aparece como usuária da ferramenta que coloca à disposição os mecanismos necessários para a organização do grupo, mas como prática social com a linguagem nos agrupamentos temáticos dos usuários da ferramenta $\mathrm{blog}$. Nesse caso, o agrupamento das pessoas on-line ocorre por meio de valores e interesses comuns, confirmando uma comunidade discursiva virtual que se traduz por uma rede eletrônica autodefinida de comunicações interativas e organizadas ao redor de interesses ou fins em comum.

A segunda característica formulada por Swales consiste na obtenção de mecanismos de intercomunicação próprios dos membros que compartilham uma determinada comunidade discursiva. Esses mecanismos variarão de acordo com os interesses do grupo e são utilizados nos processos interativos dos seus participantes, na relação que estabelecem uns com os outros, permitindo o reconhecimento de seus papéis sociais. $\mathrm{O}$ ponto aqui reafirma a questão da heterogeneidade constitutiva do discurso, pois os mecanismos de intercomunicação entre os membros de uma determinada comunidade discursiva são regidos por interesses individuais dos sujeitos que interagem nesse grupo específico. Dada a natureza dialógica, dinâmica e heterogênea da linguagem, não há como prever que os significados construídos pelo grupo representam, literalmente, isto ou aquilo.

A terceira característica consiste no uso de mecanismos participativos com o intuito de produzir informações e respostas. Está diretamente ligada à organização e à atuação dos indivíduos por meio dos mecanismos organizados socialmente. Nesse sentido, todo usuário da Internet tem a possibilidade de acessar ou não a determinada ferramenta que se encontra disponível na rede. $\mathrm{O}$ que determinará o fato de um sujeito compartilhar determinada comunidade discursiva dentro dessa rede será a sua disponibilidade de conectar-se e de agir no sentido de tomar a iniciativa de participação em um determinado grupo.

No caso dos blogs, temos um usuário da rede que tem como provedor a empresa BRTURBO. Ao entrar na página do seu provedor, ele 
é convidado a participar dos serviços oferecidos pelo mesmo; entre eles, encontra-se o link que o convida a criar o seu blog. Nesse caso, ele precisa ter a disponibilidade de acessar este link e seguir as orientações para a criação do blog. Não basta só criar, é preciso uma participação efetiva no grupo. É essa escolha individual e a participação efetiva que determinarão situar o sujeito nessa ou naquela comunidade discursiva.

A quarta característica consiste na utilização de um ou mais gêneros para estabelecer a eficácia do processo comunicativo no sentido de atingir seus objetivos. Segundo Swales, a intenção do processo de comunicação é desenvolver determinadas expectativas discursivas. Com esse propósito, os indivíduos se apropriarão de determinados mecanismos, formatos, modelos em funcionamento na comunidade discursiva. Exatamente, nesse ponto, há a correlação entre gêneros discursivos e a comunidade discursiva. É também nesse ponto que o trabalho de Swales aproxima-se da definição de gênero bakhtiniana, quando Swales se refere ao fato de que a formação de uma nova comunidade discursiva toma emprestados gêneros de outras comunidades discursivas para testar a assimilação deles no novo contexto.

Ao correlacionar esta definição com a organização dos blogs, podemos perceber claramente esse movimento de empréstimo. $\mathrm{O}$ aspecto formal da organização da página do $b \log$ e a diversidade de gêneros que ocorre nessa prática social com a linguagem confirmam a análise sobre o empréstimo de gêneros explicitado por Swales. A compreensão desse movimento fornecerá elementos para concluir se os blogs constituem ou não um novo gênero discursivo.

A quinta característica consiste em que não basta somente a posse de determinados gêneros; é necessária a aquisição de léxicos específicos. Esse ponto é muito evidenciado na nova prática social com a linguagem mediada pelo computador de uma forma geral. O processo de criação de novos léxicos tem perpassado toda a rede nas novas tecnologias da informação. Há uma dinâmica para compartilhar uma terminologia especializada com o desenvolvimento de abreviaturas específicas e termos novos da comunidade da Web. No caso dos blogs, aparecem algumas escolhas lexicais que se configuram como forma padrão nesse contexto de uso da língua, tais como: post, comentários, link. 
A última característica apontada por Swales consiste na troca dos membros para compartilhar o grau de conteúdo relevante de uma habilidade discursiva. Há uma transformação muito grande: o que determinará a sobrevivência de uma comunidade dependerá de uma relação de combate entre aquele(a) que inicia no grupo e aquele(a) que já possui larga experiência dentro do grupo.

\section{BreVe ANÁlise SObRe AS PRÁtiCAS DE LINGUAGEM SITUADAS NOS BLOGS}

Vamos considerar o formato da ferramenta que possibilita ao(à) usuário(a) do blog participar ativamente dos processos comunicativos, que inclui a marcação temporal, a construção do formato da página no sentido de buscar maior visibilidade do seu blog por meio das linguagens escolhidas, por meio de links, dos textos escritos, das imagens e sons e pelos processos interativos. Correlacionando esses aspectos com as características que definem uma comunidade discursiva, analisaremos algumas práticas sociais de linguagem em exemplos extraídos dos blogs analisados.

\subsection{QUANTO AO FORMATO DA PÁGINA}

Ao analisarmos os blogs, percebemos marcas lingüísticas que indicam a idéia de formação de uma comunidade discursiva virtual, tanto por meio da ordenação do formato físico da página na $W e b$ como pelas práticas comunicativas (escolha das linguagens utilizadas, formas de estruturação das modalidades oral e escrita, a inserção de outras linguagens e formas de interação).

$\mathrm{O}(\mathrm{a})$ produtor(a) do blog além de ter disponíveis algumas ferramentas que o ajudarão na organização do formato da página, também poderá fazer uso de caracteres criados por ele(a) próprio(a). Das formas padronizadas, encontramos algumas marcas lingüísticas que estão presentes na página inicial. Trata-se da designação do(a) produtor(a) por meio da ferramenta denominada perfil, que permite que o(a) produtor(a) do blog crie uma identidade expondo suas preferências culturais, alimentares, profissionais etc. Quanto à assinatura dos textos postados, normalmente os usuários dos blogs utilizam apelidos. Há outras referências que visam estabelecer a relação do(a) produtor(a) com o outro, por meio da disponibilidade de links que remetem a outros blogs 
(ordenados como favoritos pelo produtor do blog em análise) e também da possibilidade de mandar uma mensagem por e-mail, até mesmo pelo próprio blog por meio do link denominado comentários que será analisado a seguir.

\subsection{QUANTO AOS PROCESSOS INTERATIVOS}

Há nos blogs uma ferramenta denominada comentário e o uso desta ferramenta confirma as possibilidades de interação entre os usuários desse novo formato de comunicação. Os processos interativos estendem-se para além da ferramenta do formato do blog. Também se confirmarão nas práticas de produção dos textos postados (publicados on-line), quando os sujeitos utilizam estratégias de interação por meio do uso das linguagens escolhidas. Isso vem representado pela inserção de fotos, sinais de pontuação e, também, em determinadas estruturas sintáticas.

\section{FIGURA 1: Assinatura e COMENTÁRIO}

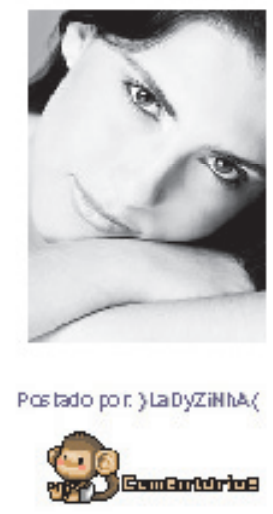

Ao analisar a Figura 1, identificamos marcas lexicais próprias desse contexto de uso da linguagem, tais como postado por, seguido da assinatura (apelido) da produtora do blog em análise )LaDyZiNhA(. Cabe observar a estruturação desta assinatura. Ela faz uso de caracteres como parênteses, maiúsculas misturadas com minúsculas. Logo após a assinatura, verificamos a imagem de um macaquinho ao lado da palavra comentários. Segundo a produtora do blog, a inserção deste macaquinho, que fica em movimento na página on-line, surgiu como possibilidade de chamar a atenção do(a) visitante 
do blog para deixar o seu comentário. Há outros recursos não-verbais disponíveis para auxiliar a estrutura verbal denominada "comentários". Há um hibridismo de linguagens, sendo que o verbal e o não verbal se unem para estabelecer a comunicação, conforme demonstrado na Figura 2, a seguir:

\section{FIGURA 2: MECANISMOS DISPONÍVEIS PARA INSERIR O LINK COMENTÁRIOS}

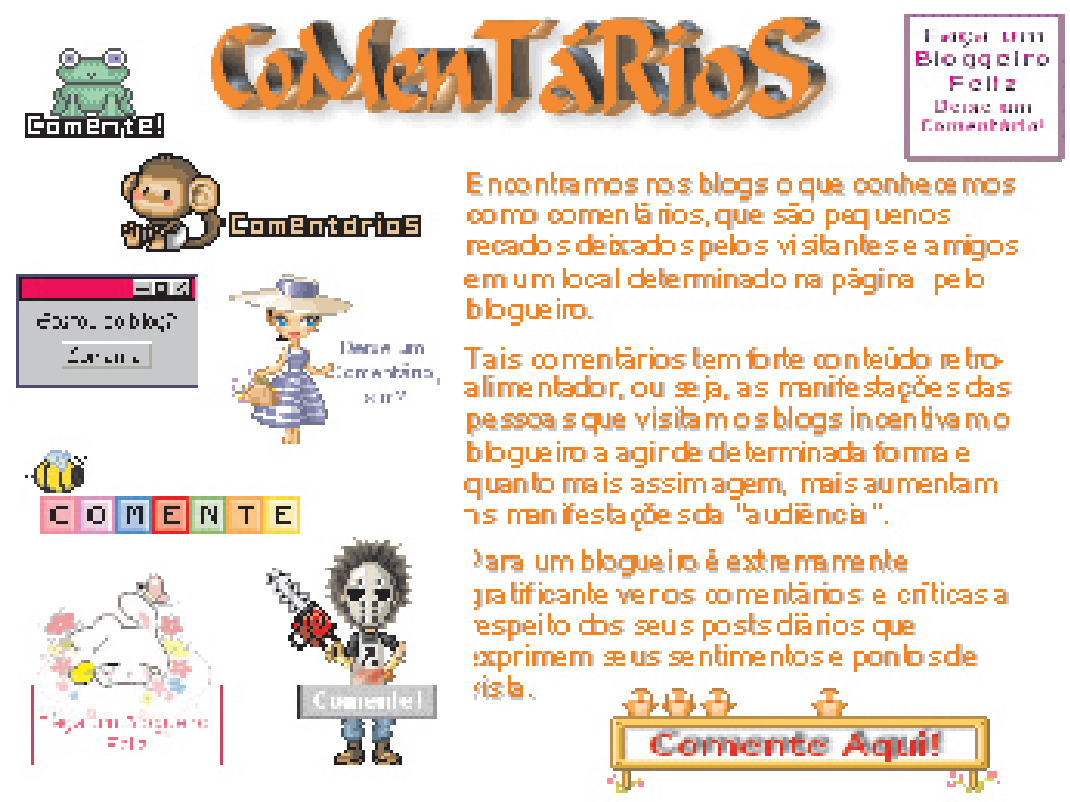

\subsection{QuANTO À INTERTEXTUALIDAdE}

O hibridismo que caracteriza os textos publicados nos blogs remete a uma relação intertextual. Considerando a intertextualidade como uma propriedade constitutiva de todo texto, dado o caráter dialógico da linguagem formulado por Bakhtin (1997), não há como deixar de mencionar os aspectos intertextuais, tanto explícitos como implícitos, presentes na relação que um texto mantém com outros textos ${ }^{4}$.

4 Ver Magalhães, I. (1996) e Rios, G. (1997). 
Nos blogs, a intertextualidade aparece tanto no formato dos textos produzidos, como por meio da ferramenta que proporciona um aspecto interativo entre os seus membros. Os indivíduos, ao linkarem e serem direcionados a outras páginas e a outros textos, estarão compartilhando informações por meio da interatividade e da intertextualidade. Vejamos como essas relações se confirmam por meio de alguns trechos selecionados do blog www.territorioneutro.blogger.com.br

- A relação eu/outro está presente nas relações intertextuais e na própria estrutura do blog ao citar, parodiar, comentar, exemplificar, parafrasear, etc.

“Adorei sua aventura...obrigada pelo carinho. Não conhecia seu lado aventureiro, mas foi muito legal ler um texto falando de vc!!!”

“Ah, Moreno... Vc com esse teu jeitinho simples de contar tuas viagens nos prende a atenção de tal maneira, que acaba ficando com gosto de "quero mais"...rss. A viagem foi muito curta...estava tão boa!!!”

- A presença do outro ocorre quando o produtor do blog estrutura seu texto, antecipando e imaginando quem é o outro que fará a leitura. Claro que o outro lerá de acordo com suas próprias referências intertextuais.

"Opa, muito interessante estas suas aventuras. Tbem curto muito viajar, mas ultimamente, por falta de $\operatorname{TEMPO}(\$ \$$ ), não ta dando. Nunca, andei de trem aqui no Brasil, mas na Europa, fiquei encantado com a organização. Já te adicionei aos meus favoritos, pois quero aprender todas as suas dicas. Abração!!” 


\section{Conclusão}

A análise das formas de comunicação utilizadas por sujeitos produtores de blogs permite-nos concluir, com base na nossa escolha teórica, que as relações dialógicas, os processos interativos e intertextuais presentes nos textos publicados nos blogs analisados são confirmados por meio do formato disponível na estrutura da página, como podemos exemplificar com o que acontece no uso da ferramenta comentários. Há um processo de constituição do sujeito por meio do uso desta ferramenta que vai ao encontro dos estudos bakhtinianos sobre o caráter dialógico da linguagem. Essa relação dialógica e interativa se completará na espera pelos comentários, constituindo uma busca constante da impressão do outro, reforçada pela idéia de Bakhtin sobre o fato de que o não-eu está presente em nós. A formação do $e u$ nas outras vozes presentes no texto é caracterizada pelo hibridismo, que marca o tratamento com a linguagem, a intertextualidade, por meio dos textos que ali circulam, a interação, por meio da relação entre as pessoas usuárias desta nova prática.

No contexto aqui apresentado, essas comunidades discursivas e virtuais criam seus próprios códigos de linguagem e formas de organização dos grupos, utilizando gêneros já existentes e recriando outras formas de gêneros marcados pelos contextos históricos, sociais, temporais que representam. Se essas comunidades estão contribuindo para a formação de novos gêneros, transformando velhas formas em outros contextos (o que não significa que os novos gêneros surgidos serão inovações puras), será possível determinar se os blogs constituem um novo gênero discursivo.

Podemos confirmar o exposto por Swales sobre o fato de que os usuários da Internet ingressam na rede ou formam agrupamentos on-line com base em interesses em comum. Além disso, dentro do segmento de usuários regulares da $\mathrm{CMC}$, tudo indica que esse veículo propicia uma comunicação mais fluida e desinibida e, com base nas estratégias comunicativas analisadas nos blogs, há uma confirmação da fluidez com que a comunicação se estabelece. 


\section{REFERÊNCIAS BIBLIOGRÁFICAS}

Bakhtin, M. Estética da criação verbal. Trad. M. E. G. Pereira. 2a ed. São Paulo: Martins Fontes, 1997.

The problem of speech genres. In.: Speech genres \& other late essays. Austin, Texas: University of Texas Press, 1996, p. 60 -102.

Castells, M. A sociedade em rede. Trad. R. V. Majer. $7^{\mathrm{a}}$ ed. rev. ampl. São Paulo: Paz \& Terra, 2003.

Cebrián, J. L. A rede. Como nossas vidas serão transformadas pelos novos meios de comunicação. Trad. L. M. Coelho. São Paulo: Summus, 1999. Fairclough, N. Discurso e mudança social. Coord. trad., revisão. e pref. à ed. bras. I. Magalhães. Brasília: Editora Universidade de Brasília, 2001. Halliday, M. A. K. \& Hasan, R. Context of situation. In: Language, context, and text. Aspects of language in a social-semiotic perspective. Oxford: Oxford University Press, 1985.

Hunt, R. Speech genres, writing genres, school genres, and computer genres. In: A. Freedman \& P. Madway (orgs.) Learning and teaching genre. Postsmouth, NH: Heinemann, 1994, p. 243-262.

Magalhães, I. Linguagem e identidade em contextos institucionais e comunitários. Cadernos de Linguagem e Sociedade, 2: 42-61, 1996.

Magalhães, I. e Leal, M. C. (orgs.). Discurso, gênero e educação. Brasília: Plano Editora: Oficina Editorial do Instituto de Letras da UnB, 2003.

Martins, A. R. Linguagem como prática social. Cadernos de Linguagem e Sociedade,6: 31-43, 2003.

Meurer, J. L. e Motta-Roth, D. (orgs.). Gêneros textuais e práticas discursivas. Bauru, SP: EDUSC, 2002.

Kress, G. e van Leeuwen, T. Reading images. Londres e Nova York: Routledge, 1996.

Pedro, E. R. (org.). Análise crítica do discurso: Uma perspectiva sociopolítica e funcional. Lisboa: Editorial Caminho, 1997.

Rios, G. V. Intertextualidade constitutiva em textos produzidos por alfabetizandos adultos em sala de aula. Cadernos de Linguagem e Sociedade, 3, (2): 27-44, 1997.

Santos, E. C. A linguagem dos blogs: Um gênero textual emergente. $\mathrm{Ca}$ - 
dernos de Linguagem e Sociedade, 6: 94-105, 2003.

Swales, J. M. Genre analysis. Cambridge: Cambridge: University Press, 1990. Versignassi, A. Weblogs reinventam o uso da Internet. Folha de S. Paulo, in http://wwre.uol.com.br, 24/1/2001.

wrwro.almagasta.blogspot.com/2002_08_01_almagasta_archive.html wrere.territorioneutro.blogger.com.br 